\title{
Inversión inmobiliaria proveniente de la minería del norte en el Gran Concepción y efectos sobre el crecimiento urbano
}

\section{Real estate investment from northern mining in the Gran Concepción and effects on urban growth}

\author{
José Prada-Trigo ${ }^{1}$, N Natalia Aravena² (1) y Pablo Barra Vieira ${ }^{3}$ (이
}

\begin{abstract}
RESUMEN
Pese a que los efectos de la actividad minera sobre el sector inmobiliario en ciudades que dependen de este rubro es un tema analizado ampliamente, el progresivo desarrollo de una conmutación de larga distancia en Chile genera nuevas consecuencias, al posibilitar la expansión por el territorio de la inversión en bienes inmuebles. En relación con ello, este artículo analiza e interpreta dicho fenómeno en el área metropolitana de Concepción mediante la combinación de encuestas a los trabajadores que se desplazan regularmente hacia el norte de Chile desde esta ciudad con entrevistas en profundidad a expertos locales. Los resultados muestran una realidad que, aunque es altamente desconocida para muchos, contribuye a reforzar el crecimiento horizontal del Gran Concepción y genera algunos desarrollos contrastados, entre una inversión en primera vivienda y que combina ahorros de la minería con ayudas públicas y otra inversión "de lujo" pero minoritaria en las áreas más exclusivas.
\end{abstract}

Palabras clave: minería, conmutación, FIFO, inversión inmobiliaria, desarrollo urbano.

\begin{abstract}
Although the effects of mining activity on the real estate sector in cities that depend on mining is already an issue analyzed, the progressive development of a long distance commuting in Chile supposes a different panorama, by enabling the expansion through the territory of investment in real estate. In this sense, this work analyzes and interprets this phenomenon in the metropolitan area of Concepción through the combination of surveys to workers who regularly travel to northern Chile from Concepción with in-depth interviews with local experts. The results show a reality that, although it is highly unknown to many, contributes to reinforce the horizontal growth of the Concepción metropolitan area and generates some contrasted developments, between an investment in first housing and that combines savings from mining with public aids, and other investment "of luxury", but minority in the most exclusive areas.
\end{abstract}

Keywords: Mining, commuting, FIFO, property investment, urban development. 
La explotación minera ha sido, históricamente, una de las fuentes de riqueza de Chile. Desde el salitre hasta el cobre, pasando por otras materias primas de menor importancia, pero con fuertes implicaciones locales (como el carbón, el oro o el molibdeno) la minería ha resultado un pilar fundamental del crecimiento económico chileno (Arellano, 2012). En el caso del cobre, el producto de mayor importancia en las exportaciones de Chile, su explotación se concentra en el norte del país. Desde Arica hasta la región de O'Higgins existen 26 grandes explotaciones de cobre con una producción aproximada de 5.500 toneladas anuales (COCHILCO, 2019). Debido al alto precio del cobre, la explotación de este mineral ha generado tradicionalmente grandes beneficios a las empresas, reflejados en elevados salarios y jugosas ventajas (seguros, becas, incentivos) para sus trabajadores, alimentando la imagen de un sector con altos sueldos y muchos beneficios (Leiva, 2009). Esto ha llevado también a algunos autores a identificar una relación entre el sector minero y los de la construcción y comercio, que crecerían como consecuencia de la reinversión de capitales provenientes de la minería en sus actividades (Rehner \& Rodríguez, 2018).

En paralelo, en diferentes países (incluido Chile) se ha producido una paulatina sustitución del modelo de "campamento minero" en las explotaciones, que implica crear construcciones físicas para alojar permanentemente a la mano de obra que llega a trabajar, por otro basado en la subcontratación de trabajadores de otras regiones y su movilización mediante un fenómeno de conmutación a larga distancia llamado FIFO, o Fly-in, fly-out (Storey, 2001). Este fenómeno, que se comenta más adelante, no solamente ha diversificado el origen de la mano de obra que trabaja en la minería, sino que también habría expandido los flujos de consumo e inversión resultantes de esta actividad hacia estas otras comunas, como trata de demostrar este trabajo.

En este contexto, el objetivo de este estudio es analizar e interpretar la magnitud, forma y consecuencias de las inversiones inmobiliarias provenientes de trabajadores de la minería del cobre en el área metropolitana de Concepción, al sur del país, entendiendo que éstas suponen una expansión de los flujos de capitales en el territorio y su materialización a través de la adquisición de viviendas para distintas finalidades. La elección del caso de estudio responde a que esta es una temática presente en estudios internacionales, pero sin apenas investigaciones desde las ciudades de origen ni desde América Latina, y con incidencia en el área metropolitana de Concepción. Dicha incidencia proviene del hecho de que Concepción se ha convertido en un nodo aeroportuario para el centro-sur de Chile, contando con vuelos directos a Antofagasta, Calama e Iquique con alta frecuencia y a que se producen movimientos regulares vinculados a la minería desde las regiones de Maule, Nuble, Araucanía e, incluso, Los Ríos y Los Lagos hacia el aeropuerto Carriel Sur para tomar estos vuelos.

En este sentido, la pregunta de investigación que mueve este trabajo es si la conmutación a larga distancia hacia el norte de Chile estaría repercutiendo en el crecimiento inmobiliario del Gran Concepción y cuáles serían sus características. Para tratar de responder a esto, se utiliza una metodología que combina la revisión bibliográfica, con el trabajo cualitativo mediante entrevistas en profundidad a expertos locales y la realización de más de 700 encuestas a trabajadores de la minería que volaban entre Concepción y las ciudades mineras del norte de Chile. A continuación, tras presentar la revisión de la literatura, la situación en cuanto a crecimiento urbano del área metropolitana de Concepción y la metodología, se analizan e interpretan los resultados, finalizándose con unas conclusiones. 


\section{Revisión de la literatura: Minería a larga distancia, FIFO e inversión inmobiliaria}

La minería es una actividad que, por su naturaleza, aparece fuertemente concentrada en algunas regiones, donde se localizan los principales yacimientos minerales (Fleming et al., 2015; Perry \& Rowe, 2015; Fernández, 2018). En ocasiones, los territorios mineros se encuentran en zonas poco pobladas, con climas extremos o escasamente comunicadas, como es el caso del norte de Chile, pero también de algunas partes de Australia o Canadá (Brueckner et al., 2013). En esas circunstancias, en el pasado las empresas mineras se instalaban cerca de los yacimientos mediante la construcción de campamentos que, a menudo, contaban con casas para los empleados, comercio y servicios (Garcés, 2003). Con ello, se buscaba suplir la falta de mano de obra, siendo origen de una fuerte vinculación de las empresas mineras con el territorio (Phelps et al., 2015). Sin embargo, la mejora y abaratamiento de los costos de transporte, las nuevas tecnologías de comunicación, y la subcontratación de muchos servicios ligados a la explotación minera (Durán-Palma \& López, 2009), han llevado a una progresiva desvinculación de las empresas mineras respecto a su entorno, produciéndose, entre otros aspectos, en una "importación" de la mano de obra, con un carácter pendular, desde otras regiones alejadas, en un movimiento que se conoce en la literatura internacional como FIFO, asimilable a un fenómeno de conmutación de larga distancia (Storey, 2001).

FIFO es un acrónimo que se refiere a los trayectos que los trabajadores vinculados a la minería realizan desde su lugar de origen, generalmente situado a gran distancia de los centros mineros, para trabajar en turnos de varios días, viajando y alojándose por cuenta de la empresa, para regresar después a sus hogares (Storey, 2001; Perry \& Rowe, 2015; Haslam \& Hoath, 2014). Esto, genera desplazamientos regulares de población hacia y desde las comunas mineras, lo que supone fuertes implicaciones sociales, laborales, económicas y espaciales. Entre las primeras, destacan los efectos sobre la vida familiar de los trabajadores, sometidos a largos períodos sin su familia, lo que generaría en ocasiones problemas de adaptación a estos turnos de trabajo (Langdon et al., 2016). En relación a las consecuencias laborales, estos desplazamientos generan ventajas para las empresas mineras, ya que los niveles de sindicalización de sus trabajadores disminuyen, reduciéndose también los costos asociados a la construcción de viviendas y servicios para ellos que desaparecen o se ven muy reducidos con el modelo FIFO, pudiéndose incluso declararse en ocasiones los costos de viaje y alojamiento como gastos de empresa en algunos países (Perry \& Rowe, 2015), lo que también supone un ahorro para la mano de obra desplazada.

Por último, en relación con los aspectos económicos y territoriales, se generaría una repartición de los riesgos de la minería a lo largo del país en caso de crisis, al no concentrarse ya los trabajadores en las zonas mineras (Aroca \& Atienza, 2011). Sin embargo, esto también supone problemas para las ciudades mineras, como una consideración negativa de los desplazamientos de larga distancia, fruto de la reducción del empleo local, tanto directo, por los trabajadores que vienen de otras regiones, como indirecto, a través del gasto que los trabajadores de la minería realizan en sus comunas de origen y que ya no se da en las zonas mineras, por lo que resulta dañino a la hora de pensar un desarrollo a largo plazo para éstas (Haslam \& Hoath, 2014; Perry \& Rowe, 2015). Algunos autores también señalan que la reducción del empleo en las ciudades mineras implica una disminución en su población residente, con consecuencias sobre la posibilidad de retener y desarrollar servicios dependientes de umbrales de población, al igual que una merma de 
la masa crítica o capital humano disponible (Perry \& Rowe, 2015). En paralelo, aumenta la presión sobre sus servicios por parte de los trabajadores que llegan a trabajar y se mantienen los efectos negativos de la actividad minera, como es el caso de los daños ambientales (Langdon et al., 2016).

Buena parte de los trabajos sobre los efectos de la minería a larga distancia se han realizado en países de gran tamaño y con áreas escasamente pobladas relacionadas con la extracción de mineral, como Australia, Canadá o Rusia (Aroca \& Atienza, 2011; Bray \& Thomson, 1992; Spies, 2006). Sin embargo, la mayoría de estos se han enfocado en las comunidades mineras, siendo escasos los trabajos que se han dirigido a analizar las consecuencias de la minería de larga distancia en las comunidades de origen (Langdon et al., 2016). En ellas, se destaca la existencia tanto de efectos positivos como negativos, señalándose entre los segundos problemas de adaptación de las economías tradicionales a estos desplazamientos de la mano de obra local, una dependencia respecto a los espacios mineros, o una falta de autonomía sobre el propio desarrollo, junto con problemas de índole social como un incremento de los divorcios, o una reducción de la implicación de los trabajadores en sus comunidades (Storey, 2010). La importancia de estos efectos y la posibilidad de analizar los mismos en espacios poco explorados, respalda el interés de esta investigación. En este sentido, varios trabajos realizados en Chile indican que una de las principales consecuencias de la minería sobre las ciudades del norte del país ha sido el auge de la actividad inmobiliaria (Rehner \& Rodríguez, 2018; Rehner et al., 2018). Sin embargo, no existen aproximaciones a los efectos de la minería de larga distancia sobre este aspecto en las comunidades de origen, lo que abre una ventana a la investigación que este trabajo trata de cubrir.

En la actualidad, al momento de referirse al peso de la inversión inmobiliaria en la economía y la expansión urbana, generalmente se toma como punto de referencia la noción al "circuito secundario de acumulación" que Henry Lefebvre proponía en los años setenta del siglo XX (Lefebvre, 1970). Este autor señalaba la existencia de un segundo circuito, paralelo al de la producción industrial, que tomaría fuerza en determinados períodos para hacer de contrapeso al estancamiento del circuito primario y la caída de su rentabilidad (op. cit.). El paso del tiempo, sin embargo, ha reforzado este segundo circuito, mediante la disminución de la rentabilidad del circuito de producción primario y la transferencia de una parte del capital desde éste hacia el circuito secundario, permitiendo absorber los excedentes del circuito primario y generar beneficios vinculados al sector inmobiliario, fijando el capital en el espacio (Harvey, 2001; De Mattos, 2016). Por ello, este sector es hoy uno de los más pujantes, con una fuerte incidencia sobre el PIB, empleo e impacto en la inversión y el gasto (Daher, 2013a).

Las propuestas de Lefebvre sobre el segundo circuito de acumulación y su incidencia en el auge de lo inmobiliario abrieron un camino de enorme importancia para la comprensión de los procesos actuales de mercantilización del crecimiento urbano (Delgadillo, 2016). En ese contexto, el sector inmobiliario y la industria de la construcción han adquirido una magnitud mucho mayor que en el pasado, haciendo que sus inversiones tengan una influencia cada día mayor en la profunda metamorfosis urbana (De Mattos, 2016). En una de las primeras investigaciones sobre los fondos de inversión inmobiliaria, se verificó su fuerte tendencia concentradora sectorial y territorial en el caso chileno, con un claro sesgo metropolitano y hacia las comunas de mayores ingresos (Daher, 2013b). Este autor se interesa en la desigual distribución intra-urbana de las inversiones inmobiliarias, ya que la evidencia empírica muestra que en los espacios urbanos donde residen los sectores de mayores ingresos y el precio de la tierra es más elevado, es donde los promotores 
e inversores inmobiliarios perciben la existencia de una mayor demanda solvente, tanto para vivienda como para servicios. Y, por tanto, es hacia estas donde se dirige el mayor volumen de las inversiones inmobiliarias. Por el contrario, las áreas de residencia de los sectores más pobres y con menor demanda solvente, reciben menos inversiones inmobiliarias (De Mattos, 2016).

Uno de los elementos que han impulsado esta situación lo constituye lo que Ricardo Méndez ha denominado como la función estratégica del mercado hipotecario (2018: 320), que se refiere a la expansión de los créditos para la compra de vivienda, bien sean privados, a través de las instituciones bancarias y de crédito, o públicos, mediante la concesión de subsidios para la adquisición de vivienda en el mercado o de exenciones fiscales. Esta prolijidad en la concesión de hipotecas actúa como un incentivo a la demanda, dinamizando el mercado inmobiliario y convirtiendo las viviendas a menudo en un activo financiero en el que invertir, con el que obtener hipotecas o generar un beneficio, a través de su arriendo o de una futura venta (Aalbers, 2016). De esta manera, determinadas áreas de la ciudad pasan a atraer con más fuerza a los compradores: los espacios centrales, las zonas residenciales de mayor calidad en la periferia o en renovaciones del centro, y los espacios con amenidades para segundas residencias o el turismo internacional, en procesos que se han expandido desde los países anglosajones hacia el sur de Europa y hacia América Latina (Janoschka \& Sequera, 2016; Borsdorf e Hidalgo, 2007; Vives-Miró, 2011). Esta situación, ha llevado a denominar el proceso de verticalización de los centros urbanos y de paralelo crecimiento "a saltos" en la periferia como de ciudad "com-fusa", en la cual el funcionamiento de los mercados del suelo produce simultáneamente una estructura urbana compacta y difusa característica de las ciudades de América Latina (Abramo, 2012).

A continuación, se analizan estas cuestiones para el caso de las inversiones inmobiliarias provenientes de los trabajadores que realizan conmutaciones de larga distancia desde Concepción, lo que resulta coherente con lo comentado hasta aquí y con algunos trabajos surgidos en los últimos años y que buscan enfocar algunas nuevas áreas de interés para la Geografía Económica, como sucede con la financiarización y el sector inmobiliario (Pike \& Pollard, 2015; De Mattos, 2016), en este caso, en relación a la conmutación de larga distancia. Pese a que la mayoría de las inversiones inmobiliarias se concentran en las principales metrópolis de cada país (Daher, 2013a), existe también un interés por interpretar qué sucede en otros espacios donde se ha producido un fuerte crecimiento inmobiliario, como Concepción. Para ello, se comienza con una breve presentación de la importancia de la minería en el país, una descripción también sucinta del crecimiento inmobiliario de Concepción, y un análisis e interpretación de la información obtenida, que permite plantear los alcances y limitaciones de este crecimiento, vinculado a la minería de larga distancia en el entorno de Concepción y sus efectos sobre el desarrollo urbano.

\section{Metodología}

Este trabajo se desarrolló mediante una metodología mixta, que buscaba aproximarse a las inversiones de los conmutadores de larga distancia de la minería a través de una doble perspectiva, cualitativa y cuantitativa. Previamente, se realizó una búsqueda bibliográfica con el fin de localizar otros trabajos internacionales vinculados a los efectos de la conmutación a larga distancia en las comunas de destino y, sobre todo, de origen, y al peso del sector inmobiliario en estos lugares. Una vez construido el marco referencial, en primer lugar, se llevó a cabo una encuesta en 
el aeropuerto Carriel Sur de Concepción. Tras contar con el permiso de la Autoridad Portuaria, un grupo de encuestadores especialmente formado para ello se desplazó diariamente durante dos semanas a encuestar a los pasajeros de un vuelo con origen Concepción y destino una ciudad minera del norte (Antofagasta, lquique o Calama, dependiendo de las frecuencias) de una de las tres aerolíneas que operan estos trayectos directamente (Latam, Sky Airlines o Jet Smart). En la sala de embarque se realizaron más de 1.800 encuestas con una primera pregunta-filtro sobre si el encuestado trabajaba en el sector minero o en alguna actividad vinculada al mismo. Se abordó directamente a los encuestados, informándoles de la finalidad de la encuesta y solicitando su colaboración. Por razones operacionales (de tiempo por encontrarse en la sala de embarque, y de volumen de encuestados) no se entregó consentimiento informado. En total, se contabilizaron 705 encuestas válidas, lo que aporta un error muestral del 3,7\% para una población infinita, con un nivel de confianza del 95\%. Posteriormente, estas encuestas, que constaban de 12 preguntas con el fin de no alargar demasiado los tiempos de embarque de los pasajeros, se procesaron y analizaron con el programa estadístico SPSS versión 22 para obtener la información que el estudio requería.

En segundo lugar, se llevó a cabo una serie de entrevistas a empresas constructoras, inmobiliarias, corredores de propiedades y expertos locales para complementar el trabajo con los datos estadísticos. En este caso, se buscaba conocer la opinión de estos actores sobre el sector inmobiliario en Concepción y su evolución durante los últimos años, y sobre el origen y destino de la demanda existente en relación al mismo. En total, los autores de este trabajo realizaron 18 entrevistas (cuadro $N^{\circ} 1$ ), utilizando primero una lista de actores-clave y aplicando posteriormente el método de "bola de nieve" para contactar con otros no detectados previamente. Esto se realizó hasta encontrar un "punto de saturación" en la información proporcionada, cuando ésta se volvía redundante. Con la finalidad de favorecer la expresión de las opiniones con mayor libertad, se decidió recurrir al anonimato en el momento de transcribir alguna parte de las entrevistas en el artículo y se le otorgó un código a cada uno de los entrevistados para su uso en este trabajo. Posteriormente, se examinaron e interpretaron las respuestas, a través del análisis de contenido, considerando que este método, por su compatibilidad con técnicas cuantitativas y por pretender, sobre todo, descubrir los componentes básicos de un fenómeno determinado (López, 2002) se adaptaba mejor a los objetivos de este trabajo.

Cuadro $\mathrm{N}^{\circ} 1$.

Actores entrevistados

\begin{tabular}{|l|l|l|}
\hline \multicolumn{1}{|c|}{ Actor } & \multicolumn{1}{c|}{ Cargo } & \multicolumn{1}{c|}{ Empresa/Gremio } \\
\hline Diego Poblete & Encargado de Estudios & Cámara Chilena de la Construcción \\
\hline Christian Kother & Gerente Comercial & $\begin{array}{l}\text { Consorcio Inmobiliario San } \\
\text { Sebastián }\end{array}$ \\
\hline Giancarlo Carro Donna & Gerente & Corredora Carro y Cía. \\
\hline Tirso Ortiz & Gerente & Corredora LG Propiedades \\
\hline Carlos Mena & Director de Proyectos VIII Región & Inmobiliaria Aconcagua \\
\hline Patricio Reyes & Gerente & Inmobiliaria Andalué \\
\hline Patricio Pacheco & Jefe Zona Sur & Inmobiliaria Armas \\
\hline Joaquín Cortés & Encargado de Ventas & Inmobiliaria FG \\
\hline Nathalie Dubois & Gerente de Desarrollo & Inmobiliaria Futuro \\
\hline
\end{tabular}




\begin{tabular}{|l|l|l|}
\hline \multicolumn{1}{|c|}{ Actor } & \multicolumn{1}{c|}{ Cargo } & \multicolumn{1}{c|}{ Empresa/Gremio } \\
\hline Roberto Schmidlin & Gerente Comercial & Inmobiliaria Futuro \\
\hline Álvaro Greene & Subgerente Comercial Centro-Sur & Inmobiliaria Icuadra \\
\hline Felipe Alcerreca L. & Gerente Comercial & Inmobiliaria Madesal \\
\hline Cristian Páez & Jefe de Ventas Zona Oriente & Inmobiliaria Paz \\
\hline Jorge Guardia & Gerente Regional & Inmobiliaria Pocuro \\
\hline Valeska Reyes & Subgerente de Ventas Zona Sur & Inmobiliaria Socovesa \\
\hline Gonzalo Chávez & $\begin{array}{l}\text { Subgerente de Desarrollo de } \\
\text { Barrios }\end{array}$ & Inmobiliaria Valmar \\
\hline Jaime Laucirica Cohn & Gerente & J.L. Gestión Inmobiliaria \\
\hline Paula Bórquez S. & Gerente & Scarabelli Propiedades \\
\hline
\end{tabular}

Elaboración propia.

\section{La minería del cobre y el crecimiento inmobiliario en Concepción}

La minería del cobre la desarrollan en Chile varias empresas privadas y una estatal: la Corporación Nacional del Cobre (CODELCO) que es la minera de cobre más grande del país y la principal productora de este metal a nivel mundial. Las minas de cobre se localizan desde la comuna de Arica, en la región de Arica y Parinacota, hasta la comuna de Rancagua, en la Región del Libertador Bernardo O'Higgins, pero la mayoría se encuentran en la región de Antofagasta (Figura № 1). De acuerdo a Atienza \& Aroca (2012), esta región recibía 16.500 trabajadores desde otras regiones, lo que representa más de $10 \%$ de su fuerza laboral, con datos del Censo de 2002. En este sentido, Jamett \& Paredes (2013), compararon la evolución de la conmutación de las regiones chilenas y su relación con el PIB per cápita regional, concluyendo que las regiones localizadas en los extremos del país y las de mayor PIB per cápita eran las que recibían un mayor flujo neto de conmutantes, siendo la región de Antofagasta, que es la de mayor PIB per cápita de todo Chile, la que mostraba un mayor aumento entre 2002 y 2009.

Entre las principales características de las regiones mineras de Chile (Tarapacá, Antofagasta, Atacama y Coquimbo) están su baja densidad poblacional y escasa oferta de fuerza laboral, suplida generalmente por la llegada de nuevos habitantes, provenientes tanto de localidades cercanas como de otras regiones del país (Rehner et al., 2018). Según Canales et al. (2018), casi el $80 \%$ de los trabajadores que se desempeñan en el sector minero conmuta desde otra región, algo que concuerda con el incremento del modelo FIFO antes comentado. En el cuadro $\mathrm{N}^{\circ} 2$ puede observarse que casi uno de cada cinco trabajadores de la región de Antofagasta está empleado en la minería, seguido de la región de Atacama. Para Aroca \& Atienza (2008), la región de Antofagasta posee algunas características que la hacen especialmente atractiva para la conmutación desde otras regiones. La primera es el alto costo de vida, ya que el alto PIB per cápita la hace un lugar caro para vivir, producto de los altos precios, la escasez de suelo existente y los mayores costos de construcción, dado su carácter periférico, lo que reduce los ingresos netos pese a los elevados salarios. 
Figura $N^{\circ} 1$.

Localización de las principales minas de cobre en Chile.

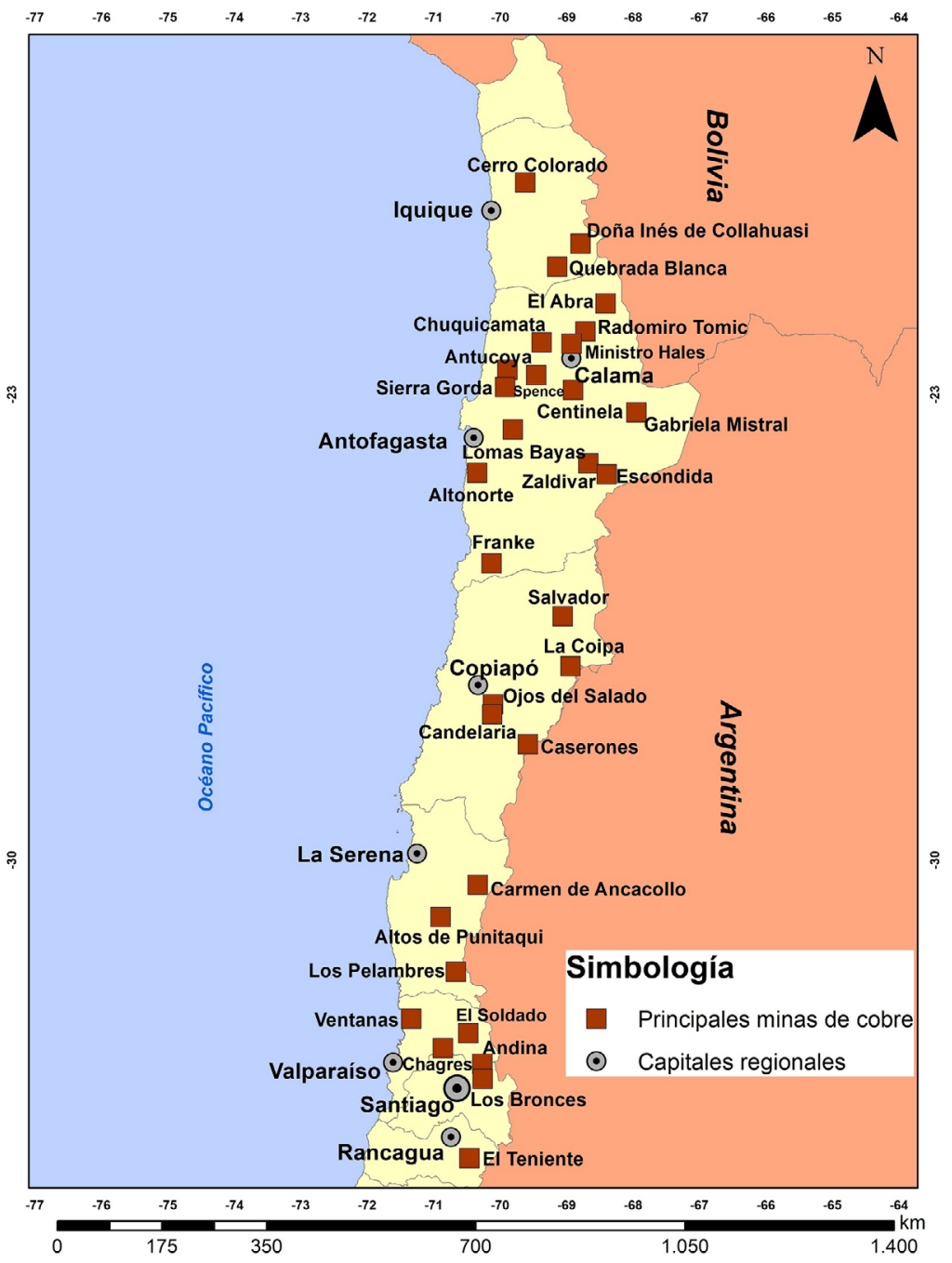

Fuente: Elaboración propia a partir de Consejo Minero (2019).

Cuadro $\mathrm{N}^{\circ} 2$.

Número de ocupados por rama de actividad económica, año 2018.

\begin{tabular}{|l|c|c|c|}
\hline \multicolumn{1}{|c|}{ Región } & $\begin{array}{c}\text { Ocupados } \\
\text { totales }\end{array}$ & $\begin{array}{c}\text { Ocupados en explotación } \\
\text { de minas y canteras (EMyC) }\end{array}$ & $\begin{array}{c}\text { Porcentaje } \\
\text { Ocupados en EMyC }\end{array}$ \\
\hline Región de Arica y Parinacota & 74.912 & 3.613 & 4,8 \\
\hline Región de Tarapacá & 166.674 & 11.067 & 6,6 \\
\hline Región de Antofagasta & 294.346 & 54.810 & 18,6 \\
\hline Región de Atacama & 142.775 & 21.952 & 15,4 \\
\hline Región de Coquimbo & 374.427 & 25.630 & 6,8 \\
\hline Región de Valparaíso & 840.343 & 23.424 & 2,8 \\
\hline Región Metropolitana & 3.431 .213 & 23.347 & 0,7 \\
\hline
\end{tabular}




\begin{tabular}{|l|c|c|c|}
\hline \multicolumn{1}{|c|}{ Región } & $\begin{array}{c}\text { Ocupados } \\
\text { totales }\end{array}$ & $\begin{array}{c}\text { Ocupados en explotación } \\
\text { de minas y canteras (EMyC) }\end{array}$ & $\begin{array}{c}\text { Porcentaje } \\
\text { Ocupados en EMyC }\end{array}$ \\
\hline Región de Bernardo O'Higgins & 421.793 & 17.066 & 4,0 \\
\hline Región del Maule & 479.197 & 3.779 & 0,8 \\
\hline Región del Biobío & 939.141 & 11.601 & 1,2 \\
\hline Región de La Araucanía & 465.532 & 233 & 0,1 \\
\hline Región de Los Ríos & 182.922 & 669 & 0,4 \\
\hline Región de Los Lagos & 417.909 & 666 & 0,2 \\
\hline Región de Aysén & 62.306 & 966 & 1,6 \\
\hline $\begin{array}{l}\text { Región de Magallanes y An- } \\
\text { tártica }\end{array}$ & 87.311 & 2.995 & 3,4 \\
\hline Total Nacional & $\mathbf{8 . 3 8 0 . 8 0 1}$ & $\mathbf{2 0 1 . 8 1 8}$ & $\mathbf{2 , 4}$ \\
\hline
\end{tabular}

Fuente: Encuesta nacional de empleo, 2018.

En segundo lugar, la región posee el mayor índice de inversión extranjera directa per cápita del país, debido a los grandes proyectos mineros que durante las dos últimas décadas se han realizado en la región. El aumento de la demanda de mano de obra y los altos salarios pagados por la minería atraen a trabajadores que, en muchos casos, deciden no establecer su residencia en la región. Este fenómeno se ve favorecido por la aplicación de sistemas de trabajo por turnos por parte de las grandes empresas mineras, que facilitan la conmutación, como se vio en el apartado anterior (Aroca \& Atienza, 2008).

Rehner et al. (2018) suponen que los ingresos generados por un sector en auge (como el minero) fomentan la realización de inversiones a largo plazo por parte de los trabajadores, adquiriendo nuevas viviendas, algo que depende de la cantidad de ingresos obtenidos y del ahorro realizado. Debido a la conmutación a larga distancia, puede suponerse que una parte de los ingresos provenientes de la minería son invertidos en otras regiones (Aroca \& Atienza 2008), aunque aún no existe evidencia al respecto ni ningún caso de estudio analizado en el contexto chileno. Por su parte, las empresas mineras también invertirían sus excedentes en actividades de construcción, vinculadas al antes mencionado circuito secundario de capital (Rehner et al., 2018). Según este enfoque, las ciudades tienen un rol clave en la reproducción del capital obtenido como renta generada por las mineras, ya que el negocio inmobiliario es considerado como un "fijo espacial" del excedente producido por esa actividad, dirigiéndose este excedente hacia las urbes, para ser allí reproducido a través de los mercados inmobiliarios.

Por su parte, el sector inmobiliario en Concepción ha experimentado un fuerte crecimiento en los últimos años, observándose un aumento de la oferta habitacional en diversas comunas como Concepción, San Pedro de la Paz, Chiguayante, entre otras (Forcael et al., 2013). Uno de los principales motores del desarrollo del Concepción Metropolitano en la última década lo representa la actividad inmobiliaria, la cual ha generado una amplia oferta de tipologías residenciales y barrios (Diario El Sur, 2017), promovida tanto por empresas locales como crecientemente por constructoras nacionales. En este sentido, los permisos de edificación aprobados en el área metropolitana habrían sufrido un incremento notable desde comienzos del siglo XXI hasta la actualidad, como puede observarse en la Figura $N^{\circ} 2$. En la misma, se aprecian distintos momentos de crecimiento inmobiliario, el primero entre los años 2005 y 2006, que coincide con la nueva política habita- 
cional del Ministerio de Vivienda y Urbanismo (MINVU), y después entre los años 2010 y 2011, producto de un efecto post terremoto, donde se buscaba reconstruir la ciudad con nueva infraestructura habitacional. Sin embargo, lejos de disminuir bruscamente, se habría mantenido un ritmo de crecimiento superior al período previo a 2010.

Figura $\mathrm{N}^{\circ} 2$.

Permisos de Edificación aprobados en el Concepción Metropolitano (Número de Viviendas), años 2002-2015.

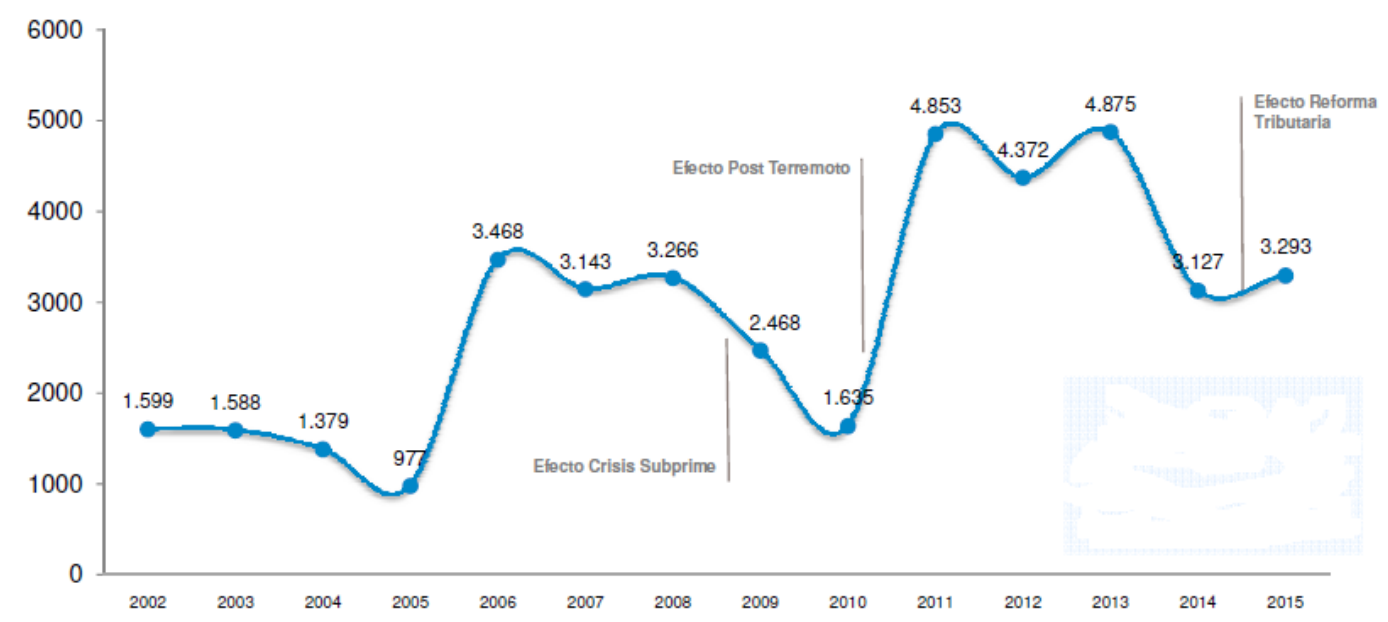

Fuente: GFK ADIMARK (2016)

El área metropolitana de Concepción (figura $\mathrm{N}^{\circ} 3$ ), habría tenido transformaciones importantes durante la segunda mitad del siglo XX. En lo físico, la constante expansión urbana y la creciente conurbación ha hecho evidente el carácter unitario y metropolitano, así como la necesidad de la planificación conjunta (Salinas y Pérez, 2011). En los últimos años, el AMC muestra un importante crecimiento en términos de superficie urbana, que implica modificaciones en la estructura y localización del suelo urbanizado: la ocupación urbana central predominante, Concepción-Talcahuano, se ha extendido, cruzando la barrera del Biobío y sumando San Pedro de la Paz. El proceso más importante de localización de nuevo tejido es en la periferia de esta comuna, en un proceso de expansión y conurbación, intensificando la conexión con una segunda corona formada por Chiguayante y Penco, que se adivina también en municipios más alejados como Coronel, Lota y Tomé (op. cit.). El resultado sería un policentrismo espacialmente restringido, donde ciudades descentralizadas administrativamente, como San Pedro de la Paz y Chiguayante, son atractivas para el uso residencial, pero a su vez muy dependientes de los lugares centrales, especialmente en puestos de trabajo y servicios (Rojas et al., 2009). Para estos autores, el AMC nunca ha funcionado como un modelo monocéntrico propiamente tal, aunque se reconoce que la influencia de Concepción tiende a mantenerse, debido a la importante concentración de servicios y equipamientos metropolitanos. 
Figura $\mathrm{N}^{\circ} 3$.

Localización del área metropolitana de Concepción

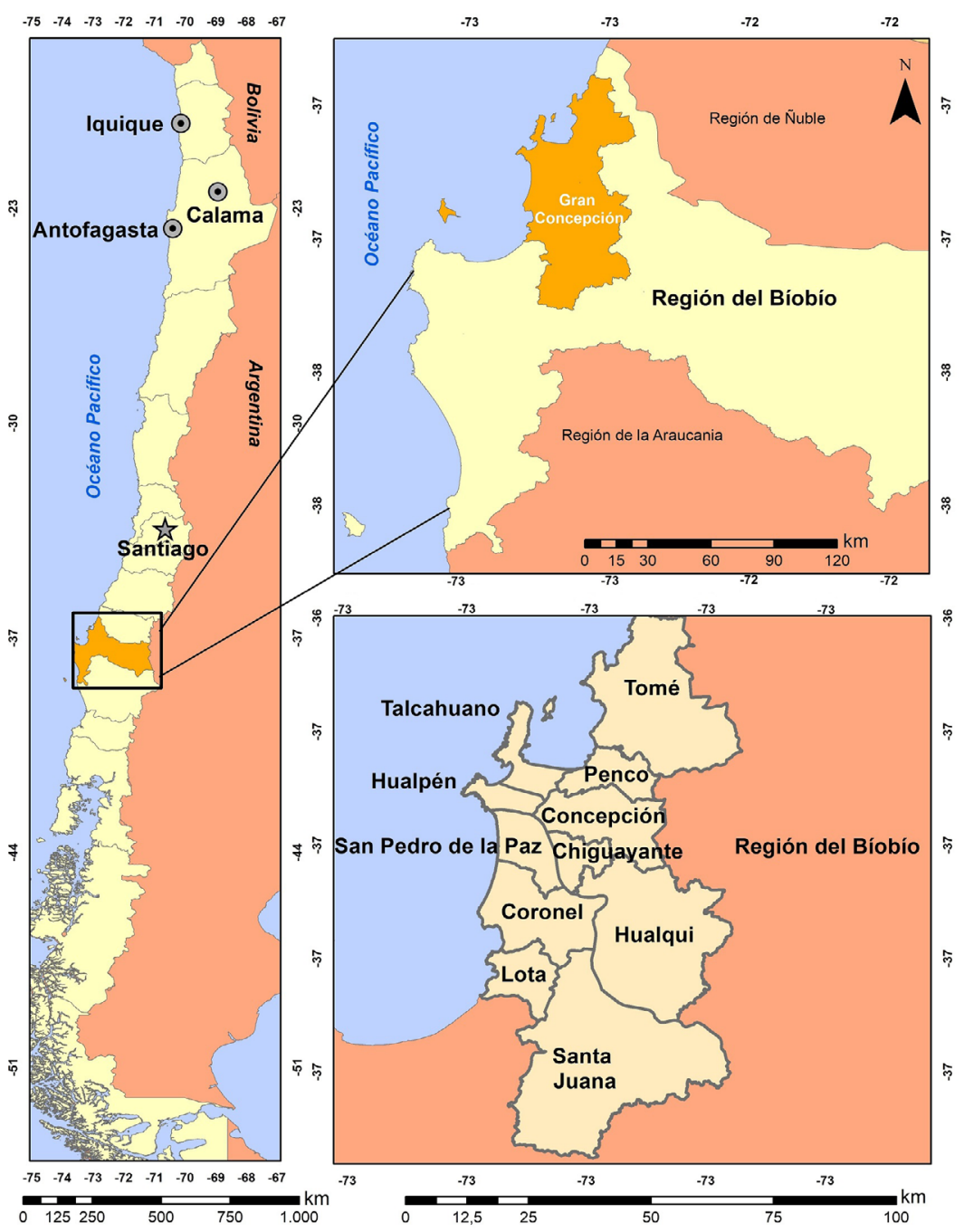

Elaboración propia.

De esta forma, en los últimos años, el Concepción Metropolitano ha experimentado un crecimiento urbano horizontal (en sus límites urbanos) y al mismo tiempo vertical (en su centro) producto del aumento de la inversión inmobiliaria (Forcael et al., 2013). Ejemplo de este último es el centro de Concepción, donde los proyectos de edificios de departamentos desplazan progresivamente a los barrios tradicionales formados por casas (Diario La Tercera, 2017). A nivel metropolitano, sin embargo, el crecimiento suburbano contribuiría de alguna manera a equilibrar esta situación, habiéndose vendido en 2017 un total de 3.500 departamentos frente a 2.500 casas (Diario Concepción, 2018). Así, por un lado, el mercado inmobiliario en altura tuvo una revitalización en el centro de Concepción debido a la limitación de la oferta del suelo para expansión urbana en la comuna, que genera mayores costos de suelo y viviendas más caras. A esta situación debe sumar- 
se la política pública de subsidios habitacionales, como el DS 19, que favorecen la construcción de edificios en altura. Por otro lado, en comunas pertenecientes al área metropolitana, como San Pedro de la Paz, Penco y Coronel, continúa un modelo de expansión urbana horizontal, debido a que disponen aún de gran superficie de suelo destinado a la construcción, por lo que son predominantes las casas dirigidas a diferentes estratos sociales dependiendo del sector.

Esta forma expansiva de crecimiento genera nuevas urbanizaciones periféricas, como el sector Ribera Norte (Pérez \& Salinas, 2009), las Lomas de San Sebastián, de San Andrés, Bellavista, o el Sector Paicaví (que se ha desarrollado a partir de la autopista Concepción-Talcahuano). En este sentido, Rojas et al. (2009) indican que las nuevas manchas urbanas se habrían localizado en torno al río Biobío, primero mostrando un crecimiento de tipo concéntrico o radial asociado a nuevas zonas residenciales en comunas cercanas a Concepción y después de manera más desordenada, con un crecimiento a saltos o en islas. Junto con esto, la comuna de Concepción se ha consolidado en el desarrollo de actividades terciarias, contando con servicios administrativos, profesionales, educacionales y financieros, aspectos que la hacen atractiva para la inversión inmobiliaria (Baeriswyl, 2007). También hay que mencionar su peso como ciudad universitaria, ya que la alta presencia de estudiantes en la zona ha impulsado la compra de departamentos como inversión, atrayendo a inversionistas "hormigas" que buscarían una renta fija mediante su arriendo, o un alojamiento para sus hijos mientras estudian en la universidad. Sin embargo, pese a existir información sobre la evolución del mercado inmobiliario del Gran Concepción, se evidencia una ausencia de datos que expliquen el origen y componentes de la demanda del mismo, que en el caso concreto de este trabajo se porta para explicar el peso de las inversiones provenientes de la minería del cobre.

\section{Análisis de la Información}

A partir de las encuestas realizadas, se filtraron aquellas correspondientes a trabajadores de empresas directa o indirectamente relacionadas con la minería, que son las que se utilizan en este punto. Un primer conjunto de preguntas arroja información sobre el perfil del trabajador. La primera característica de éstos es su fuerte masculinización $(94,4 \%$ de los casos) y el predominio de una cohorte de edad de adultos en edad intermedia ( 26 a 45 años, correspondiente al $68,2 \%$ de los casos) por sobre cohortes más jóvenes (3,7\%) o maduras (28,1\%). En cuanto al origen, un $11,5 \%$ de los trabajadores provienen de Concepción, seguido de Talcahuano (9\%), San Pedro $(8,4 \%)$, Coronel (7,7\%) y Los Ángeles (6,1\%). En total, el área metropolitana de Concepción suponía el $59 \%$ del total de trabajadores encuestados, cuyo origen se extendía desde San Clemente (Maule) hasta Puerto Montt, aunque el grueso pertenecía a las regiones de Nuble, Bíobio y Araucanía. En relación con el tipo de empleo, se reconoce un claro componente de periodicidad en el mismo, siendo la relación más común un empleo periódico por turnos $(83,1 \%)$ sobre los desplazamientos intermitentes $(16,9 \%)$, resultando predominante que éste se trate de un empleo de subcontratación, y de servicios anexos u externos a la actividad minera. Lo primero se relaciona directamente con el abaratamiento de los modos de transporte, y la alta competencia en vuelos low cost en el mercado aéreo chileno, mientras que la segunda idea guarda relación con la tercerización y segmentación de actividades al interior de las empresas, que facilita esta modalidad de empleo. Al respecto, ACT2 señalaba que los profesionales que estudian acá se empiezan a quedar más acá, 
no como antes, y empiezan a tener más poder adquisitivo y a generar sus familias acá, y van y salen [...] a Antofagasta, a la zona de la minería.

También se puede destacar que la antigüedad del empleo entre los encuestados no es demasiado elevada, habiendo trabajado en su mayoría desde unos meses hasta 5 años (39,7\%), sumando el total de los trabajadores con menos de 10 años el 75,3\% de los casos, lo que hace que la media de años trabajando en la minería sea de 8,7. Este dato es asimilable a una conmutación de larga distancia que resulta reciente, y que coincide con el comienzo de los vuelos denominados low cost en Chile, lo que daría una respuesta a la necesidad de importación de mano de obra por parte de la industria minera, permitiéndoles desvincularse de su medio directo e "importar" mano de obra más barata y con menos posibilidades de sindicalización desde otras regiones del país, como se indicaba en la revisión de la literatura.

Más allá de las características de estos trabajadores, como se señalaba en la revisión de la literatura, resulta de interés conocer los efectos de la conmutación de larga distancia sobre el mercado inmobiliario en los lugares de origen de estos. En este sentido, el 38,3\% de los sujetos entrevistados indicaba haber comprado o invertido en bienes inmobiliarios en el Gran Concepción, realizando estas inversiones a partir de su trabajo en la minería, lo que se traduce en un trasvase de recursos desde las regiones mineras, hacia regiones situadas en el sur del país, lo que equivale en el área metropolitana de Concepción a cerca de 260 inversiones sobre un total de 705 encuestas. Según lo indicado por los entrevistados ACT15, ACT 17 y ACT 2, existe una coincidencia en que la capacidad crediticia de quien trabaja en la minería es mayor:

[ACT15] La minería... empezó hace 2 años, 3 años [después de] un frenazo importante y ahí también trajo secuelas acá, porque la gente de Concepción, los penquistas que tenían sus familias acá, se iban a trabajar allá 10 por 5 , no sé cómo son esas salidas-bajadas, estos "gallos" venían y ipum! compraban 2 departamentos, una casa, y dejaban sus familias armadas y volvían. Después había un paro, les pagaban plata y ipum! [compraban un] departamento. Entonces ellos estaban invirtiendo mucho, venían y compraban autos nuevos, entonces hasta en eso se notó.

Dichas inversiones inmobiliarias se han realizado en su mayoría, según la encuesta, en las comunas de San Pedro de la Paz (19,76\%), Talcahuano (15,81\%), Coronel $(15,01 \%)$, Chiguayante $(12,64 \%)$ y Concepción $(13,43 \%)$, coincidiendo con los lugares de residencia de los trabajadores, pero también con las principales zonas de expansión urbana del Gran Concepción, así como con las comunas que poseen más oportunidades de subsidio estatal para la compra de inmuebles por ser espacios donde la mayor perificidad y disponibilidad de suelo implican menores costos de éste (figura $\mathrm{N}^{\circ} 4$ ). Asimismo, entre las principales zonas en que se ha invertido en inmuebles dentro de las comunas del área metropolitana, se destacan los sectores de Lomas de San Andrés en Concepción, Concepción Centro, Lomas Coloradas en San Pedro de la Paz, Lagunillas y Escuadrón en Coronel. Tales áreas han tenido un auge inmobiliario en los últimos años, de acuerdo con los permisos de edificación 2002-2015, particularmente después del 27F, con los subsidios asociados a la reconstrucción y el impulso al crecimiento urbano que se ha mantenido en los años posteriores. El aumento en la oferta habitacional, junto con las nuevas políticas de desarrollo social para el acceso a vivienda, sumado a la posibilidad de conmutación del empleo en una activi- 
dad más rentable como lo es la minería en el contexto nacional, darían como resultado un cliente objetivo, que invierte en la actividad inmobiliaria, sosteniendo con ello el crecimiento urbano en los sectores mencionados.

Figura $N^{\circ} 4$.

Inversiones según tipo de vivienda y cantidad invertida por comuna en el Área Metropolitana de Concepción

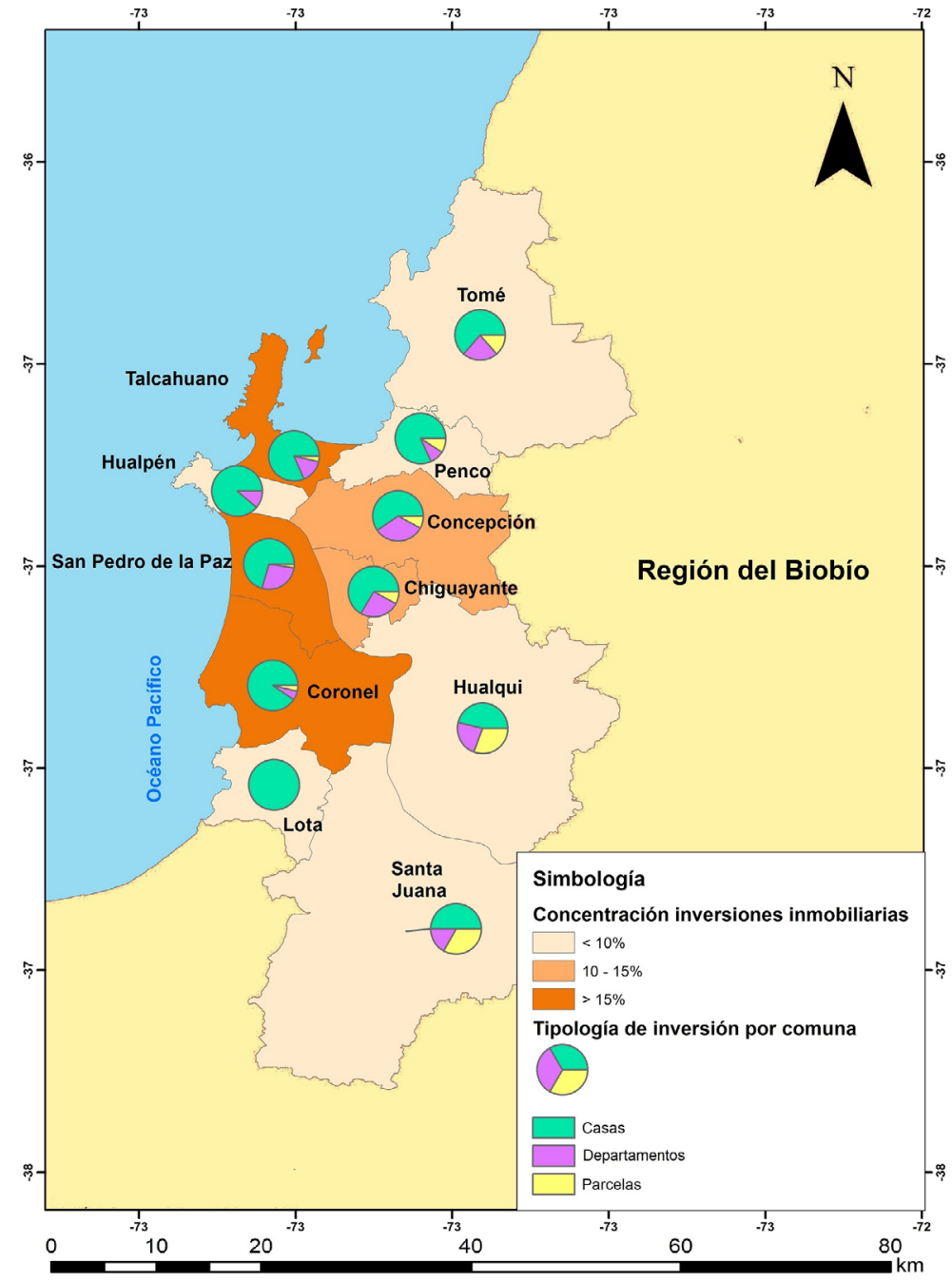

Elaboración propia a partir de datos de la encuesta.

En relación con el tipo de inmueble, la inversión más recurrente es en casas, alcanzando un $81,9 \%$ de los casos, mientras que para los departamentos las inversiones corresponden a un 15,11\% de las adquisiciones. Frente a ello, los terrenos urbanos tienen menor peso (apenas $0,4 \%$ ), al igual que las parcelas rurales $(2,6 \%)$. Los encuestados comentaban que esto se debe al hecho de que, en muchos casos, se trataba de la primera inversión en un bien inmueble, como casa para la familia, y que recibieron subsidio público para acceder a ese tipo de inmueble, considerándose 
mejor la "vida de barrio" para la familia, que privilegiar vivir más cerca del centro de la ciudad en las zonas de verticalización y densificación urbana. También se explica porque el costo de una casa en las zonas de expansión del área metropolitana como San Pedro de la Paz, Talcahuano y Coronel, es menor y más susceptible a aportes estatales que un departamento con los mismos metros cuadrados construidos en comunas centrales. Por último, el hecho de que la mayoría de trabajadores llevase menos de 10 años en el sector de la minería y tenga una edad entre 26 y 45 años, también puede explicar la preferencia por una primera vivienda bajo la modalidad de casa por delante de otras opciones (segunda residencia, departamento para arriendo, etc.), lo que se entiende según el entrevistado ACT15 en tanto hoy día la gente se proyecta hasta 5 años en una casa, porque calculan que en 5 años más van a tener un delta [mayor ingreso] y se pueden cambiar. Es decir, se compra una primera residencia pensando en cambiarse después al tener más poder adquisitivo, dejando esa primera vivienda como inversión.

Lo anterior se refleja claramente en el destino de la inversión, ya que en el 74,9\% de los casos responde a una inversión cuya finalidad es la residencia principal, lo que guarda relación con que ésta aparezca como una casa en los sectores de expansión urbana del área metropolitana. Existe una correlación positiva moderada $(0,43)$ de acuerdo al análisis bivariado de Pearson entre el tipo de vivienda en el que se invierte y el destino de dicha inversión, lo que se condice con lo comentado por los encuestados en relación a su primera inversión en inmueble como residencia familiar y que de preferencia se trata de una casa, o en su defecto que el subsidio estatal se les otorgue específicamente para una casa en las zonas de expansión urbana. La segunda categoría guarda relación con la necesidad de contar con una segunda residencia, lo que explica el 9,8\% de las inversiones. Muy próximo $(10,1 \%)$ se encuentra la compra para arrendar, sea de manera general o a los estudiantes que llegan a estudiar a la ciudad (que por sí sólo explican casi un 2,5\% de las compras de vivienda de los conmutadores). Según los actores se reconoce que el arriendo para estudiantes es un motor de inversión, como indica ACT15: sí, eso [arriendo a estudiantes] es evidente cerca de las universidades, en Concepción centro... compran departamentos de un dormitorio, sin estacionamiento, tiene que ser caminable. Por último, con un 2,5\% de los arriendos en cada caso, se encuentra el comprar una vivienda a los hijos, o en construir en un terreno o en una parcela existente (que puede vincularse también a segundas residencias).

Además, es posible relacionar los datos anteriores con los montos de inversión o cantidad invertida: el $52,9 \%$ de los casos tiene un monto total invertido en el sector inmobiliario de menos de 50 millones de pesos, lo que podría responder a dos razones. En primer lugar, a que la mayoría de los encuestados eran trabajadores subcontratados de edad intermedia, por lo tanto, sus ingresos no son tan altos comparados con el empleo directo y de más edad en el rubro minero, ni se encontraría con una gran capacidad de inversión. En segundo lugar, a que el monto máximo para acceder al subsidio estatal es cercano a las 2000 UF ( 55 millones de pesos aproximadamente) y para los encuestados buena parte de los inmuebles adquiridos tienen aporte estatal mediante subsidios, por lo que los montos invertidos no pueden ser superiores a esa cantidad. Como puede apreciarse en el cuadro $N^{\circ} 3$, conforme aumenta el rango etario, también aumenta el peso porcentual en inversiones de mayor envergadura. Por el contrario, los menores de 25 años no realizan ninguna inversión superior a 100 millones de pesos, con lo que un mayor número de años trabajando implicaría una mayor cantidad a invertir en el sector inmobiliario, lo que tendría implicancias a su vez en el sector en el cual invierten, destacándose San Pedro de la Paz y Coronel. 
Cuadro $\mathrm{N}^{\circ} 3$.

Inversiones realizadas según cantidad invertida y rango de edad del inversor (porcentaje)

\begin{tabular}{|l|c|c|c|c|c|}
\hline \multirow{2}{*}{ Inversión } & \multicolumn{4}{|c|}{ Rango de edad del comprador } & \multirow{2}{*}{ Total } \\
\cline { 2 - 5 } & $\mathbf{1 5}$ a 25 años & $\mathbf{2 6}$ a 45 años & $\mathbf{4 6}$ a 60 años & Más de 60 años & \\
\hline Menos de 50 millones & 2,5 & 65,5 & 31,9 & 0,0 & 100 \\
\hline De 50 a 100 millones & 1,2 & 68,2 & 29,4 & 1,2 & 100 \\
\hline Más de 100 millones & 0,0 & 47,1 & 49,0 & 3,9 & 100 \\
\hline Total & $\mathbf{1 , 6}$ & $\mathbf{6 2 , 7}$ & $\mathbf{3 4 , 5}$ & $\mathbf{1 , 2}$ & $\mathbf{1 0 0}$ \\
\hline
\end{tabular}

Elaboración propia.

Al realizar un análisis cruzado según el tipo de vivienda en el que invierten los trabajadores mineros y en que comuna del Concepción Metropolitano se localiza su inversión (cuadro $N^{\circ} 4$ ), se observa que ninguna comuna sobresale en el caso de las casas, sino que estas se reparten entre San Pedro de la Paz, Concepción, Coronel y Talcahuano. Sin embargo, en el caso de los departamentos destacan Concepción y San Pedro de la Paz, que cuenta con un reciente fenómeno de verticalización (Schovelin, 2013). En relación a las parcelas rurales, el $26 \%$ se localiza en Concepción, aunque Chiguayante y Hualqui engloban el $30 \%$, siendo éstas comunas más alejadas del centro metropolitano utilizadas típicamente como áreas de expansión de las segundas residencias. Existen tres comunas en las que el número de parcelas rurales supera las otras categorías: Tomé, Hualqui y Santa Juana, sectores considerados como de expansión en el futuro del desarrollo inmobiliario en el área metropolitana y como espacios destinados al ocio, según las entrevistas realizadas.

Cuadro $\mathrm{N}^{\circ} 4$.

Propiedades (totales y porcentuales) según tipología en la que invierten los trabajadores mineros en las comunas del Concepción Metropolitano.

\begin{tabular}{|l|c|c|c|c|c|c|}
\hline \multirow{2}{*}{ Comuna } & \multicolumn{2}{|c|}{ Casa } & \multicolumn{2}{c|}{ Departamento } & \multicolumn{2}{c|}{ Parcela rural } \\
\cline { 2 - 7 } & Total & Porcentaje & Total & Porcentaje & Total & Porcentaje \\
\hline Concepción & 53 & 18 & 29 & 33 & 7 & 26 \\
\hline San Pedro de la Paz & 62 & 21 & 24 & 27 & 2 & 7 \\
\hline Talcahuano & 44 & 15 & 8 & 9 & 2 & 7 \\
\hline Chiguayante & 34 & 11 & 13 & 15 & 4 & 15 \\
\hline Penco & 9 & 3 & 1 & 1 & 1 & 4 \\
\hline Hualpén & 16 & 5 & 2 & 2 & 0 & 0 \\
\hline Coronel & 47 & 16 & 3 & 3 & 2 & 7 \\
\hline Lota & 9 & 3 & 0 & 0 & 0 & 0 \\
\hline Tomé & 14 & 5 & 5 & 6 & 3 & 11 \\
\hline Hualqui & 6 & 2 & 3 & 3 & 4 & 15 \\
\hline Santa Juana & 3 & 1 & 1 & 1 & 2 & 7 \\
\hline Total & $\mathbf{2 9 7}$ & $\mathbf{1 0 0}$ & $\mathbf{8 9}$ & $\mathbf{1 0 0}$ & $\mathbf{2 7}$ & $\mathbf{1 0 0}$ \\
\hline
\end{tabular}

Fuente: Elaboración propia.

Finalmente, el financiamiento de la inversión inmobiliaria de los entrevistados proviene parcial o totalmente de la minería en un $95,55 \%$ de los casos. Se destaca en esta respuesta la importancia 
del subsidio estatal para las inversiones que provienen parcialmente de la minería $(24,4 \%)$. Este financiamiento desde la minería hacia la inversión inmobiliaria en la región de origen se traduce en un movimiento de los flujos de capital en el espacio y una ampliación de la influencia de una actividad económica que se cree muy asociada al norte del país, pero cuyas consecuencias se extienden en el mercado hipotecario hacia ámbitos más amplios. Al considerar solamente las grandes inversiones habitacionales realizadas por los trabajadores mineros (aquellas de más de 100 millones de pesos), y el sector donde se localizan estas, se ofrecen unos resultados con determinados matices. En el cuadro $N^{\circ} 5$, puede observarse cómo la mayoría de estas inversiones se concentran en Concepción y San Pedro de la Paz (abarcando más del 50\%). Le siguen Talcahuano y Chiguayante, que en conjunto suponen 17 inversiones, lo que equivale al $25 \%$ del total. Entre las áreas de inversión, se nombran las Lomas de San Sebastián y de San Andrés (Concepción), y el barrio Andalué (San Pedro de la Paz), sectores conocidos por encontrarse entre los más exclusivos dentro de la metrópolis (Schovelin, 2013). Se observa que las grandes inversiones se concentran en las comunas centrales de la metrópolis, en cambio Lota y Santa Juana (localizadas en los límites) no son de interés para inversiones de este tamaño, estableciéndose una clara diferencia respecto al grueso de las inversiones, como se indicaba en la revisión de la literatura.

Cuadro $N^{\circ} 5$.

Propiedades (totales y porcentuales) con un monto de inversión desde 100 millones de pesos en las comunas del Concepción Metropolitano.

\begin{tabular}{|l|c|c|}
\hline Comuna & Propiedades totales & Porcentaje \\
\hline Concepción & 18 & 27 \\
\hline San Pedro de la Paz & 20 & 30 \\
\hline Talcahuano & 7 & 10 \\
\hline Chiguayante & 10 & 15 \\
\hline Penco & 1 & 1 \\
\hline Hualpén & 1 & 1 \\
\hline Coronel & 5 & 7 \\
\hline Lota & 0 & 0 \\
\hline Tomé & 2 & 3 \\
\hline Hualqui & 2 & 3 \\
\hline Santa Juana & 1 & 1 \\
\hline Total & $\mathbf{6 7}$ & $\mathbf{1 0 0}$ \\
\hline
\end{tabular}

Fuente: Elaboración propia.

Al separar estas inversiones por rangos monetarios (cuadro $N^{\circ} 6$ ), continúa la predominancia de San Pedro de la Paz y Concepción junto a Chiguayante en todos los subgrupos. Los resultados coinciden con lo expresado por Daher (2013b), quien afirma que en los espacios urbanos donde residen los sectores de mayores ingresos y el precio de la tierra es más elevado, es donde los promotores e inversores inmobiliarios perciben la existencia de una mayor demanda solvente, tanto para vivienda como para servicios. Y, por tanto, es hacia estas donde se dirige el mayor volumen de las inversiones inmobiliarias. Esto conlleva que sean más atractivos para la población, con mejor dotación de servicios e infraestructura, lo que genera un mayor desarrollo. Por el contrario, las áreas de residencia de los sectores de baja demanda solvente, reciben menos inversiones inmobiliarias, generándose territorios "olvidados", donde los servicios básicos son escasos y la 
conectividad con el centro es dificultosa y poco expedita, además de poseer una infraestructura habitacional precaria.

Cuadro $\mathrm{N}^{\circ} 6$.

Propiedades (totales y porcentuales) por rango de inversión en las comunas del Concepción

Metropolitano.

\begin{tabular}{|l|l|l|l|l|l|l|}
\hline \multirow{2}{*}{ Comuna } & \multicolumn{2}{|c|}{ De $\mathbf{1 0 0}$ a $\mathbf{1 5 0}$ millones } & \multicolumn{2}{c|}{ De 150 a 200 millones } & Más de 200 millones \\
\cline { 2 - 8 } & Total & Porcentaje & \multicolumn{1}{|c|}{ Total } & Porcentaje & Total & Porcentaje \\
\hline Concepción & 8 & 29 & 4 & 25 & 6 & 26 \\
\hline San Pedro de la Paz & 8 & 29 & 6 & 38 & 6 & 26 \\
\hline Talcahuano & 2 & 7 & 2 & 13 & 3 & 13 \\
\hline Chiguayante & 6 & 21 & 1 & 6 & 3 & 13 \\
\hline Penco & 0 & 0 & 0 & 0 & 1 & 4 \\
\hline Hualpén & 0 & 0 & 0 & 0 & 1 & 4 \\
\hline Coronel & 3 & 11 & 1 & 6 & 1 & 4 \\
\hline Lota & 0 & 0 & 0 & 0 & 0 & 0 \\
\hline Tomé & 0 & 0 & 1 & 6 & 1 & 4 \\
\hline Hualqui & 0 & 0 & 1 & 6 & 1 & 4 \\
\hline Santa Juana & 1 & 4 & 0 & 0 & 0 & 0 \\
\hline Total & $\mathbf{2 8}$ & $\mathbf{1 0 0}$ & $\mathbf{1 6}$ & $\mathbf{1 0 0}$ & $\mathbf{2 3}$ & $\mathbf{1 0 0}$ \\
\hline
\end{tabular}

Fuente: Elaboración propia.

En cuanto a las grandes inversiones inmobiliarias realizadas por los trabajadores mineros en el resto del país (cuadro $N^{\circ} 7$ ) las zonas predilectas de estas son las ciudades de Antofagasta, Calama (ambas zonas mineras) y Santiago. En el caso de la capital nacional, aunque estudios demuestran su importancia inmobiliaria y conmutativa (López, 2013; Canales et al. (2018), para los trabajadores mineros que se desplazan desde Concepción al norte del país, no es un destino muy atractivo para invertir en inmuebles en relación al importante mercado de la vivienda que existe en la capital del país. A continuación aparecen otros destinos vinculados a la minería (Iquique) o a lugares de atractivo turístico en Chile como La Serena, Viña del Mar o Pucón (Hidalgo et al., 2016), junto con la capital de la cercana región de Ñuble.

\section{Cuadro $\mathrm{N}^{\circ} 7$.}

Número de propiedades con un monto de inversión desde 100 millones de pesos en otras comunas de Chile.

\begin{tabular}{|c|c|}
\hline Comuna & Propiedades totales \\
\hline Antofagasta & 18 \\
\hline Calama & 11 \\
\hline Santiago & 10 \\
\hline Chillán & 4 \\
\hline Viña del Mar & 4 \\
\hline lquique & 3 \\
\hline La Serena & 2 \\
\hline Pucón & 2 \\
\hline Otras comunas & 1 \\
\hline
\end{tabular}

Fuente: Elaboración propia. 


\section{Conclusiones}

Los resultados de este trabajo evidencian que el dinamismo de la conmutación a larga distancia vinculado a la minería está generando una expansión de la movilidad a lo largo del territorio chileno, con la aparición de ciudades como Concepción que actúan como charnela a la hora de captar y redirigir flujos de trabajadores que vienen de los alrededores de este centro urbano para dirigirse hacia las explotaciones mineras del norte. Como se ha podido comprobar en las encuestas, la mayoría de los conmutantes son población joven, con una trayectoria laboral relativamente reciente y que, posiblemente, por tratarse de cuadros medios u operativos, recurren a la minería como "ayuda" para adquirir su primera vivienda, lo cual contrasta con la clásica imagen de los trabajadores de la minería como grandes inversores. En realidad, a tenor de los resultados de la encuesta, estos resultan pocos y corresponden con las personas de mayor edad y número de años dedicados al trabajo en la minería. Una razón de esto, puede deberse a que los grandes inversores (ejecutivos, cuadros medios y altos y directivos) se concentren en Santiago y no tanto en las regiones de Chile.

Entre las razones para este auge de los desplazamientos a larga distancia se encuentra la búsqueda por parte de las mineras de mano de obra a menor costo, junto con la aparición de vuelos low cost entre regiones, y la diferencia del salario percibido (Paredes et al., 2018), origen de flujo de trabajadores que migran desde Concepción hacia el norte, aprovechando el mejor sueldo para invertir en el sector inmobiliario. Éstas, a raíz de las respuestas obtenidas, se concentran en Concepción, San Pedro de la Paz, Talcahuano, Coronel y Chiguayante, comunas centrales del Gran Concepción. En cambio, sectores más distantes del núcleo de la metrópolis, como Hualqui, Lota y Santa Juana son las que poseen menos propiedades contabilizadas en las encuestas realizadas y muy volcadas hacia parcelas rurales, lo que muestra una preferencia por comprar viviendas en la capital regional, posiblemente por el atractivo de ésta como centro de servicios.

Otro aspecto importante es que, aunque el trabajo de campo mediante entrevistas reveló un fuerte fenómeno de verticalización del centro de Concepción, también detectado en la prensa regional y en algún trabajo previo (Rojas et al., 2009), los datos de las encuestas indicaban que las inversiones provenientes de la minería estarían contribuyendo preferentemente a la expansión horizontal del área urbana, incidiendo en el crecimiento metropolitano, como parte de la formación de una ciudad "com-fusa" (Abramo, 2012) en Concepción. El tipo de inversor, relativamente joven pero con edad suficiente para tener familia, y con poca trayectoria en el sector minero, podrían explicar la preferencia por casas destinadas a primera vivienda y financiadas también con subsidios públicos. No obstante, como se ha podido comprobar en las entrevistas, para las inmobiliarias más activas en la zona y las corredoras de propiedades, un cliente objetivo clave para su producto es el inversionista hormiga. El mismo, que decide invertir en un departamento para arrendar, responde a diversas tipologías, pero una de ellas es la del trabajador que se emplea en el norte del país, como se ha señalado, contribuyendo el minero, bien por la compra de departamento o por la de casas, al crecimiento inmobiliario de Concepción.

Por lo tanto, este trabajo ha permitido detectar la presencia, escasamente estudiada, de capitales provenientes de la minería en zonas alejadas de las comunas mineras y destinados a la adquisición de viviendas. Los resultados evidencian la importancia de los subsidios públicos a la compra de vivienda en el fenómeno de inversión inmobiliaria ligado a la minería, muy vinculado a 
las características de los trabajadores, así como el papel protagónico que tienen ciudades como Concepción a la hora de favorecer la movilidad de espacios más alejados, permitiendo a su vez una inversión inmobiliaria en los mismos. Finalmente, esta investigación, más allá de los aportes que realiza en sí misma, puede suponer un avance a la hora de comprender las complejas consecuencias que actividades como la minería tienen en el territorio a diferentes escalas a través de flujos de capitales, que resultan intangibles pero que tienen su materialización espacial en el crecimiento urbano de las ciudades.

\section{Referencias}

AALBERS, M. The Financialization of Housing. A political economy approach. Londres: Routledge, 2016.

ABRAMO, P. La ciudad com-fusa: mercado y producción de la estructura urbana en las grandes metrópolis latinoamericanas. EURE, 2012, Vol.38, №114, p. 35-69. http://www.eure.cl/index.php/ eure/article/view/68

ARELLANO, J. P. El cobre como palanca del desarrollo para Chile. Estudios Públicos, 2012, №127, p. 123-159. https://www.cepchile.cl/el-cobre-como-palanca-de-desarrollo-para-chile/cep/201603-04/100017.html

AROCA, P. \& ATIENZA, M. Economic implications of long distance commuting in the Chilean mining industry. Resources policy, 2011, Vol.36, N³, p. 196-203. https://www.sciencedirect.com/ science/article/pii/S0301420711000225

AROCA, P. \& ATIENZA, M. La conmutación regional en Chile y su impacto en la Región de Antofagasta. EURE, 2008, Vol.34, N¹02, p. 97-121. https://repositorio.uc.cl/handle/11534/4102

ATIENZA, M., \& AROCA, P. Concentración y crecimiento en Chile: una relación negativa ignorada. EURE, 2012, Vol.38, Nº114, p. 257-277. https://repositorio.uc.cl/handle/11534/4181

BAERISWYL, S. Patrones de ocupación del Gran Concepción. A través del modelo de consumo de suelo. En: Coloquio del País Urbano al País Metropolitano. Santiago, 2007.

BORSDORF, A. \& HIDALGO, R. New dimensions of social exclusion in Latin America: From gated communities to gated cities, the case of Santiago de Chile. Land Use Policy, 2007, Vol.25, N², p. 153-160. https://www.sciencedirect.com/science/article/pii/S026483770700049X

BRAY, M. \& THOMSON, A. At the end of the shift: mines and single industry towns in Northern Ontario. Toronto: Dundurn Press, 1992.

BRUECKNER, M; DUREY, A; MAYES, R. \& PFORR, C. The mining boom and Western Australia's changing landscape: Towards sustainability or business as usual? Rural Society, 2013, Vol.22, №2, p. 111-124. https://www.tandfonline.com/doi/abs/10.5172/rsj.2013.22.2.111 
CANALES, A., CANALES, M., \& HERNÁNDEZ, M. Trabajo y territorio en el nuevo agro chileno. Un estudio de commuters en tres comarcas del Valle Central. EURE, 2018, Vol.44, №131, p. 5-28. https:// www.eure.cl/index.php/eure/article/viewFile/2120/1049

COCHILCO - Comisión Chilena del Cobre. Estadísticas de producción minera. Santiago: 2019. Disponible en internet: https://www.cochilco.cl/Paginas/Estadisticas/Bases\%20de\%20Datos/Producci\%C3\%B3n-Minera.aspx

CONSEJO MINERO. Mapa Minero. Santiago: 2019. Disponible en internet: https://consejominero. cl/wp-content/uploads/2017/09/mapa-minero-para-descarga-1.pdf.

DAHER, A. Fondos inmobiliarios y riesgo urbano. Revista de Urbanismo Universidad de Chile, 2013b, Vol.15, N²9, p.32-45. https://revistas.uchile.cl/index.php/RU/article/download/30303/32087/

DAHER, A. Territorios de la financiarización urbana y de las crisis inmobiliarias. Revista de Geografía Norte Grande, 2013a, N56, p. 7-30. http://dx.doi.org/10.4067/S0718-34022013000300002

De MATTOS, C. Financiarización, valorización inmobiliaria del capital y mercantilización de la metamorfosis urbana. Sociologias, 2016, Vol.18, N42, p. 24-52.

DELGADILLO, V. Financiarización y mercantilización del desarrollo urbano en escala planetaria. Entrevista a Carlos A. de Mattos. Andamios, 2016, Vol.13, N³2, p. 213-243. https://andamios.uacm. edu.mx/index.php/andamios/article/view/530

DIARIO CONCEPCIÓN. ¿Nuevo boom? En 2017 se vendieron 6.000 viviendas en el Gran Concepción. 2018, Disponible en internet: https://www.diarioconcepcion.cl/economia-y-negocios/2018/02/04/ nuevo-boom-en-2017-se-vendieron-6-000-viviendas-en-el-gran-concepcion. html.

DIARIO EL SUR. El desarrollo urbano del Gran Concepción. 2017, Disponible en internet: http:// www.elsur.cl/impresa/2017/04/08/full/edicion-especial/7/.

DIARIO LA TERCERA. Edificaciones en altura abren debate urbano en Concepción. 2017, Disponible en internet: https://www.latercera.com/noticia/edificaciones-altura-abren-debate-urbano-concepcion/.

DURÁN PALMA, F. \& LÓPEZ, D. Contract labour mobilisation in Chile's copper mining and forestry sectors. Employee Relations, 2009, Vol.31, N³, p.245-263. https://www.emeraldinsight.com/ doi/10.1108/01425450910946451

FERNÁNDEZ, V. Copper mining in Chile and its regional employment linkages. Resources Policy, 2018, Disponible en internet: https://doi.org/10.1016/j.resourpol.2018.03.017

FLEMING, D.; MEASHAM, T \& PAREDES, D. Understanding the resource curse (or blessing) across national and regional scales: Theory, empirical challenges and an application. Australian Journal 
of Agricultural and Resource Economics, 2015, Vol.59, p. 624-639. https://onlinelibrary.wiley.com/ doi/full/10.1111/1467-8489.12118

FORCAEL, E.; ANDALAFT, A.; SCHOVELIN, R. \& VARGAS, P. Application of the real options valuation method to estate projects. Revista Obras y proyectos, 2013, Vol.14, p.58-70. http://www.realoptions.org/openconf2018/data/papers/203.pdf

GARCÉS, E. Las ciudades del cobre: Del campamento de montaña al hotel minero como variaciones de la company town. EURE, 2003, Vol.29, N88, p.131-148. https://repositorio.uc.cl/handle/11534/3952

GFK ADIMARK. Cifras del mercado inmobiliario Gran Concepción y sus perspectivas. Santiago, Chile: Área de Estudios Territoriales, 2016.

HARVEY, D. Globalization and the Spatial Fix, Geographische Revue, 2001, Vol.2, p.23-30. https:// publishup.uni-potsdam.de/files/2251/gr2_01_EssO2.pdf

HASLAM, F. \& HOATH, A. The socio-economic impact of mine industry commuting labour force on source communities. Resources policy, 2014, Vol.42, p.45-52. The socio-economic impact of mine industry commuting labour force on source communities.

HIDALGO, R., et al. En las costas del neoliberalismo. Naturaleza, urbanización y producción inmobiliaria: experiencias en Chile y Argentina. Santiago de Chile: Serie GEOlibros N²3, Instituto de Geografía, Pontificia Universidad Católica de Chile -Instituto de Geografía, Pontificia Universidad Católica de Valparaíso, 2016.

INSTITUTO NACIONAL DE ESTADÍSTICAS (INE) (2019). Censo de población y Vivienda 2017. Disponible en: http://resultados.censo2017.cl/ Consultado: 15/02/2019.

JAMETT, I., \& Paredes, D. Conmutación de larga distancia en Chile: Estimando el premio por trabajar muy lejos de casa. Estudios de economía, 2013, Vol.40, №2, p.179-209. http://econ.uchile.cl/ uploads/publicacion/a79a69b021acdad7ae569cc332cc74126158ddf1.pdf

JANOSCHKA, M. \& SEQUERA, J. Gentrification in Latin America: addressing the politics and geographies of displacement, Urban Geography, 2016, Vol.37, Nº, p.1175-1194. https://www.tandfonline.com/doi/abs/10.1080/02723638.2015.1103995

LANGDON, R., BIGGS, H., \& ROWLAND, B. (2016). Australian fly-in, fly-out operations: Impacts on communities, safety, workers and their families. Work, 2016, Vol.55, p.413-427. https://www.ncbi. nlm.nih.gov/pubmed/27689595

LEFEBVRE, H. La revolution urbaine. Paris: Gallimard, 1970.

LEIVA, S. La subcontratación en la minería en Chile: elementos teóricos para el análisis. Polis, 2009, N²4, p.1-18. Disponible en internet: http://journals.openedition.org/polis/1540 
LÓPEZ, E. Gentrificación en Chile: aportes conceptuales y evidencias para una discusión necesaria. Revista de Geografía Norte Grande, 2013, Vol.56, p.31-52. http://repositorio.uchile.cl/handle/2250/145533

LÓPEZ, F. El análisis de contenido como método de investigación. Revista de Educación, 2002, Vol.4, p. 167-179.

MÉNDEZ, R. La telaraña financiera. Una Geografía de la financiarización y su crisis. Santiago: Ril Editorial, 2018.

MINISTERIO DE VIVIENDA Y URBANISMO (MINVU) (2003). Plan Regulador Metropolitano de Concepción. Memoria Explicativa. Disponible en: https://www.prmconcepcion.cl Consultado: 20/02/2019.

PAREDES, D.; SOTO, J. \& FLEMING, D. Wage compensation for fly-in/fly-out and drive-in/drive-out conmuters. Papers in Regional Science, 2018, Vol.97, N4, p.1337-1353. https://onlinelibrary.wiley. com/doi/abs/10.1111/pirs.12296

PÉREZ, L. \& SALINAS, E. Fragmentos de ciudad. Formas de crecimiento del Concepción Metropolitano. En: Hidalgo, R.; De Mattos, C. Y Arenas, F. (Eds.) Chile: del país urbano al país metropolitano. Santiago: Instituto de Geografía, Instituto de Estudios Urbanos y Territoriales, Pontificia Universidad Católica de Chile, 2009, p. 269-300.

PERRY, M. \& ROWE, J. E. Fly-in, fly-out, drive-in, drive-out: The Australian mining boom and its impacts on the local economy. Local Economy, 2015, Vol.30, №1, p.139-148. http://journals.sagepub. com/doi/abs/10.1177/0269094214564957

PHELPS, N.; ATIENZA, M. \& ARIAS, M. Encore for the Enclave: The Changing Nature of the Industry Enclave with Illustrations from the Mining Industry in Chile. Economic Geography, 2015, Vol.91, No2, p. 119-146. https://onlinelibrary.wiley.com/doi/abs/10.1111/ecge.12086

PIKE, A. \& POLLARD, J. Economic Geographies of Financialization. Economic Geography, 2010, vol 86, №1, p. 29-51. https://onlinelibrary.wiley.com/doi/abs/10.1111/j.1944-8287.2009.01057.x

REHNER, J. \& RODRÍGUEZ, S. Cities built on copper - The impact of mining exports, wages and financial liquidity on urban economies in Chile. Resources Policy. 2018. https://doi.org/10.1016/j. resourpol.2018.05.001.

REHNER, J., RODRÍGUEZ, S., \& MURRAY, W. Ciudades en auge en Chile: Rol de la actividad exportadora en la dinámica del empleo urbano. 0, 2018, Vol.44, N¹31, p.151-172. https://scielo.conicyt. cl/scielo.php?script=sci_arttext\&pid=S0250-71612018000100151

ROJAS, C., MUÑIZ, I. \& GARCÍA, M. Estructura urbana y policentrismo en el Área Metropolitana de Concepción. EURE, 2009 Vol.35, Nº105, p. 47-70. https://dx.doi.org/10.4067/S025071612009000200003 
ROJAS, C.; OPAZO, S. \& JAQUE, E. Dinámica y patrones de crecimiento urbano del Área Metropolitana de Concepción. Tendencias de las últimas décadas. En: HIDALGO, R.; DE MATTOS, C. Y ARENAS, F. (eds.) Chile: del país urbano al país metropolitano. Santiago: Instituto de Geografía, Instituto de Estudios Urbanos y Territoriales, Pontificia Universidad Católica de Chile, 2009, p. 257-268.

SALINAS, E. \& PÉREZ, L. Procesos urbanos recientes en el Área Metropolitana de Concepción: transformaciones morfológicas y tipologías de ocupación. Revista de geografía Norte Grande, 2011, Vol.49, p. 79-97. https://dx.doi.org/10.4067/S0718-34022011000200006

SCHOVELIN, R. Modelo para maximizar ingresos de nuevos proyectos inmobiliarios, por medio de la selección de la mejor combinación de atributos y características de las viviendas, para una determinada localización. Tesis para obtener el grado de Doctor en Gestión y Valoración Urbana, Escuela técnica superior de arquitectura de Barcelona, Universidad Politécnica de Cataluña, Barcelona, España, 2013.

SPIES, M. Distance between home and workplace as a factor for job satisfaction in the North-West Russian oil industry. Fennia - International Journal of Geography, 2006, Vol.184, №2, p.133-149. https://fennia.journal.fi/article/view/3724 